\title{
The effects of terminal food and water deprivation on the reinforcing properties of light-onset ${ }^{1}$
}

JACK T. TAPP, DONNA M. MATHEWSON, and PAULA JARRETT, ${ }^{2}$ Vanderbilt University, Nashville, Tenn. .37203

To test the hypothesis that increases in need increase rats' tendencies to react to stimuli, groups of acutely food- or water-deprived rats and ad lib controls were tested in a double bar lever-pressing apparatus. One lever produced the onset of a dim light; the other lever served as a control. Both deprived groups preferred the lever which turned on the light to a greater extent than the ad lib group, supporting the hypothesis. The food-deprived animals emitted more total responses than the ad lib or water-deprived groups.

According to the Campbell \& Sheffield hypothesis (1953) increases in hunger do not increase activity per se, but lower the response threshold for those stimuli which normally instigate activity. In other words, activity in the rat represents a reaction to environmental stimuli. Deprivation enhances the tendency to react to these stimuli. More recently Campbell (1964) has extended these results and demonstrated that water deprivation produces effects that are similar to those observed for food deprivation under the appropriate test conditions.

Confirmation of this hypothesis has received only partial support from studies designed to investigate the effects of food and water deprivation on the reinforcing properties of light-onset. Several experimenters (Davis, 1958; Segal, 1959; Premack \& Collier, 1962; Tapp \& Simpson, 1966) have reported that food deprivation increased the rate of bar pressing for light-onset, yet others (Forgays \& Levin, 1958; Wilson, 1962; Kiernan, 1965; Smith \& Donahoe, 1966) have found that food deprived rats did not respond at higher rates for light-onset than ad lib controls. Similar conflicting results have been reported for the effects of water deprivation on light-contingent bar pressing (Kling, Horowitz, \& Delhagen, 1956; Clay ton, 1958).

The following experiment was conducted to examine the effects of terminal food and water deprivation on the reinforcing properties of light-onset. Terminal deprivation was used to continually increase deprivation states and to avoid possible confounds that might arise from cues that become conditioned to daily feeding and watering. These deprivation conditions also have the effect of keeping body weight changes the same for both food and water deprived animals (Campbell, 1964).

\section{METHOD}

The apparatus consisted of four identical $9 \times 12 \times 15$ in. clear Plexiglas boxes with $1 / 8$-in. stainless steel grid floors, housed in gutted refrigerator cabinets to reduce incident light and noise. Two aluminum levers, $1 \mathrm{in}$. wide and $3 \mathrm{in.} \mathrm{long,}$ protruded $1 \frac{1}{2}$ in. into each box and were mounted $1 \frac{1}{2} \mathrm{in}$. above the floor on opposite ends of the boxes. The levers were mounted on a relay contact assembly to minimize their operation noise and were adjusted to move through a distance of $12 \mathrm{~mm}$ with a force of $25 \mathrm{~g}$. A 71/2-W light bulb mounted on the inside wall of each refrigerator cabinet 6 in. above each lever was adjusted to yield a light intensity of $.5 \mathrm{ft}-\mathrm{L}$ at a center point of the apparatus equidistant from both levers. The apparatus was programmed such that one lever in each box would turn on the adjacent light for the duration of the response. The opposite lever produced no light-onset and served as a control lever. The position of the light-contingent lever was systematically counterbalanced over all experimental groups.

The Ss were 24 naive male albino Holtzman rats, 120 days of age at the start of the experiment, randomly assigned to one of the experimental groups. On Day 1, the animals were placed in the apparatus for $2 \mathrm{~h}$. During this period food was removed from the home cages of one third of the animals; water was removed from the cages of another third. These animals did not receive food or water until the experiment was terminated. The remaining animals were maintained on ad lib food and water in their home cages. Each animal was tested at the same time daily for a 2 -h session for a total of 10 consecutive days. Responses on both levers for all boxes were recorded on moving paper tape and scored for each $15-\mathrm{min}$ time period for all 10 sessions.

\section{RESULTS}

The mean daily responses of the three groups for all 10 days of the experiment are summarized in Fig. 1. The analysis of variance performed on these data substantiate the conclusions that are apparent from the examination of Fig. 1. The food deprived animals responded more on both levers than the water deprived or ad lib groups $(F=5.02, \mathrm{df}=2,21, \mathrm{p}<.02)$. In general, the animals in all groups responded more on the lighted bar than on the non-lighted bar $(F=39.47, \mathrm{df}=1,21$, $p<.001)$ but this tendency changed differentially for each group over the 10 days of the experiment $(F=2.06$, $\mathrm{df}=$ $18,189, \mathrm{p}<.01)$.

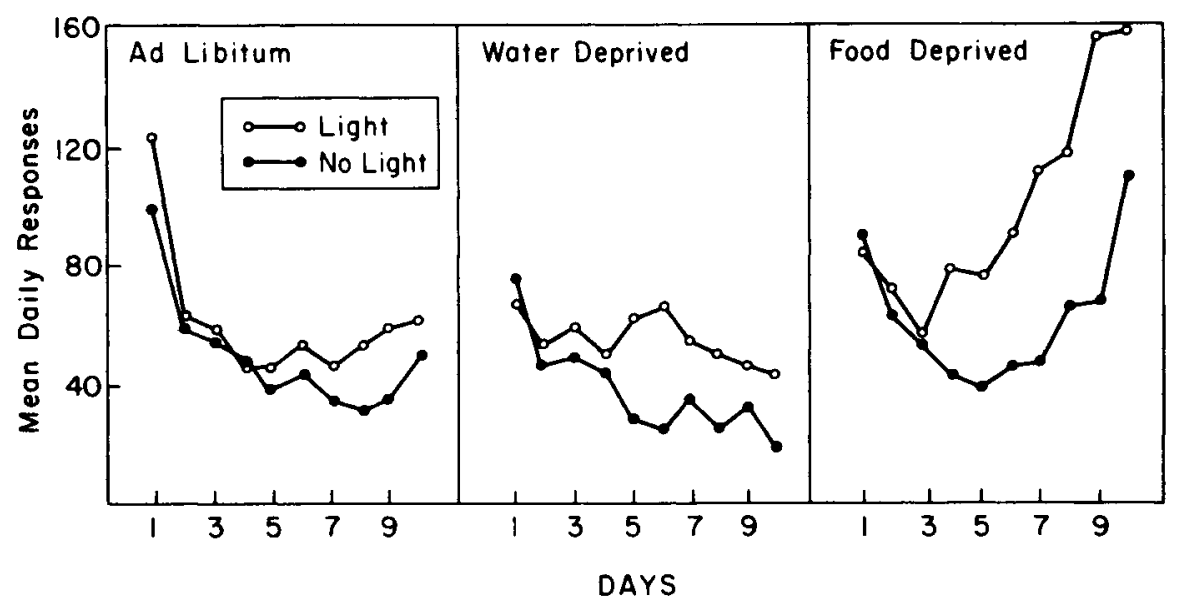

Fig. 1. Mean daily levels of responding computed over the $2-h$ daily test sessions. Deprivation was continuous for the 10 days of the experiment. 


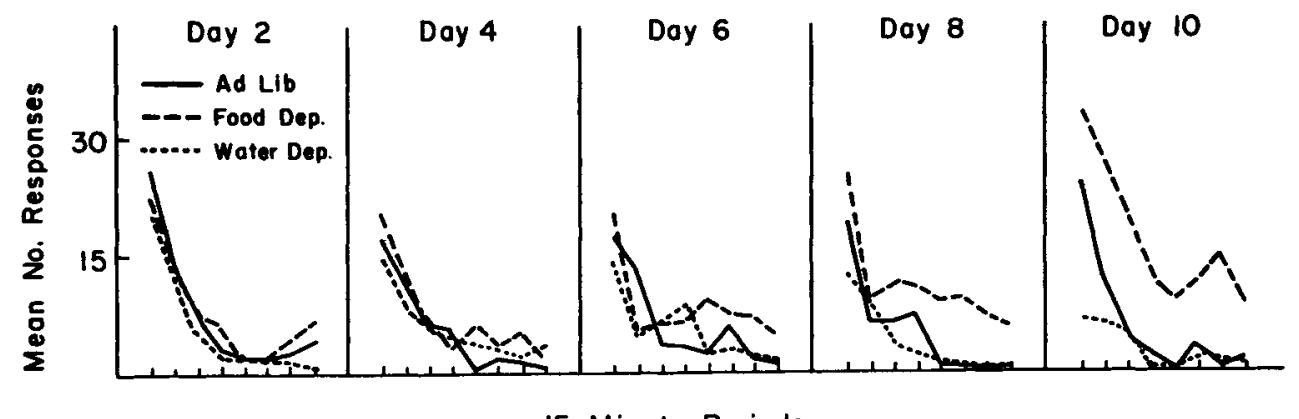

15 Minute Periods

Fig. 2. Response decay curves plotted for each 15 -min period of the 2-h sessions for the days indicated. The ordinate is based on the mean number of responses on both levers combined.

To analyze these differential levels of responding on the lighted and nonlighted bars, preference scores were computed for each group for each day of the experiment by subtracting the total responses on the nonlighted control lever from responses on the light-contingent lever. Analysis of these scores revealed that none of the groups significantly preferred either lever on Days $1,2,3,4$, or 6 . The food and water deprived groups preferred the light reinforced lever on Days 5 , $7,8,9$, and 10 while the ad lib group exhibited a reliable preference for that lever only on Days 8 and 10 ( $t$ test for correlated means $p<.05$ ). Furthermore, the food deprived group showed a significantly greater preference for the lighted lever than the other groups on Days 7, 9, and 10 (Mann-Whitney U, p <.05).

The differential total levels of responding that were observed for the food deprived animals was due, primarily, to their tendency to continue responding at high rates throughout the total test session $(F=1.80, d f=126,1323$, $p<.01)$. This result is summarized in Fig. 2 which shows the mean daily response for each $15 \mathrm{~min}$ period for all three groups for the even numbered days of the experiment. This change in the rate of response decay over the 10 days of the experiment was not differential for the lighted and nonlighted levers $(\mathrm{F}=1.16, \mathrm{df}=126,1323, \mathrm{p}>.10)$.

\section{DISCUSSION}

The interpretations of the results of this experiment are dependent on the assumption that the reinforcing properties of light-onset are a measure of the rats' reactance to environmental stimuli. This assumption is supported by those experiments in which no change in stimulation follows a response (Tapp \& Simpson, 1966). In these conditions, groups of rats respond at similar levels and rate increases only when light-onset is made contingent with a response. The fact that all three groups in the present experiment responded at higher levels on the lever which produced light-onset also supports this assumption. These observations attest to the validity of the fundamental assumption of the Campbell and Sheffield hypothesis, i.e., activity in the rat occurs as a reaction to environmental stimuli. However, it should be pointed out that under the conditions of the present study, light-onset was not reinforcing for any group until the animals had been tested in the apparatus for several days. This is in contrast to other studies on the rewarding properties of light-onset in which it has typically been reported that light-onset is reinforcing for all groups of animals. Any or all of three factors may contribute to these differential results: (a) the amount of adaptation to the test apparatus (Kiernan, 1965), (b) the duration of the test session, and (c) the magnitude of the response necessary to produce light-onset (Tapp \& Simpson, 1966). Until these factors have been examined in more detail, their relative contributions to this phenomenon remain a matter for speculation.

The results of the present experiment also support the hypothesis that increases in need lower the rats' threshold to respond to environmental stimuli. Both the food and water deprived groups showed similar behaviors since a reliable preference for the lever which produced light-onset was exhibited earlier in the testing sequence for these groups than for the deprived animals. This result suggests that both hunger and thirst lower the rats' threshold to react to those changes in environmental stimuli that occur as a consequence of its behavior. This interpretation is consistent with data reported by Campbell (1964) which indicates that terminal food and water deprivation increase activity in the activity wheels and in unstable stabilimeter cages.

Food and water deprivation differ from one another in their effects on the total levels of responding in this apparatus. The hungry animals were much more responsive over the total 2-h session than the thirsty or ad lib animals. Similar differences between the effects of hunger and thirst have been noted by other investigators. The mechanisms which underlie the differential effects of hunger and thirst on response output are not readily apparent and warrant further investigation.

\section{REFERENCES}

CAMPBELL, B. A., \& SHEFFIELD, F. D. Relation of random activity to food deprivation. Journal of Comparative \& Physiological Psychology, $1953,46,320-322$.

CAMPBELL, B. A. Theory and research on the effects of water deprivation on random activity in the rat. In M. J. Wayner (Ed.), Thirst. New York: Macmillan, 1964.

CLAYTON, F. L. Light reinforcement as a function of water deprivation. Psychological Reports, 1958, 4, 63-66.

DAVIS, J. D. The reinforcement effect of weak light onset as a function of the amount of food deprivation. Journal of Comparative \& Physiological Psychology, 1958, 51, 496-498.

FORGAYS, D. G., \& LEVIN, H. Learning as a function of change in sensory stimulation. I. Food-deprived vs food-satiated animals. Journal of Comparative \& Physiological Psychology, 1958, 51, 50-54.

KIERNAN, C. C. Effect of food deprivation and unconditional operant pretests on bar pressing on light in the albino rat. Journal of Comparative \& Physiological Psychology, 1965, 60, 168-271.

KLING, J. W., HOROWITZ, L., \& DELHAGEN, J. E. Light as a positive reinforcer for rat responding. Psychological Reports, 1956, 2, 337-340.

PREMACK, D., \& COLLIER, G. Analysis of nonreinforcement variables affecting response probability. Psychological Monographs, 1962, 76, 5 (Whole No. 524).

SEGAL E. F. Confirmation of a positive relation between deprivation and the number of responses emitted for light reinforcement. Journal of the Experimental Analysis of Behavior, 1959, 2, 165-169.

TAPP, J. T. \& SIMPSON, L. L. Motivational and response factors as determinants of the reinforcing value of light onset. Journal of Comparative \& Physiological Psychology, 1966, 62, 143-146.

WILSON, J. J. Photic reinforcement as a function of optimal level of stimulation. Psychological Record, 1962, 12, 17-23.

SMITH, K. C., \& DONAHOE, J. W. The effects of food deprivation on unreinforced and light-reinforced bar pressing. Journal of Genetic Psychology, 1966, 108, 213-219.

\section{NOTES}

1. This research was supported, in part, by Research Grant MH-07265, Training Grant MH-08 107, and NSF Grant GE-6302.

2. Miss Jarrett was an undergraduate NSF summer trainee at Vanderbilt University during the conduct of this experiment. Her current address is Fisk University, Nashville, Tennessee. 